\title{
Reatividade in vitro de lipase submetida a diferentes tratamentos tecnológicos
}

[Reactivity in vitro of the lipase submitted to different technological treatments]

\author{
V.P.A. Ferreira ${ }^{1}$, W.M. Ferreira ${ }^{2}$, E.O.S. Saliba ${ }^{2}$, A.O. Teixeira ${ }^{3}$ \\ ${ }^{1}$ Centro de Gestão Empreendedora - FEAD - Minas \\ Rua Claúdio Manoel, 1162, Funcionários \\ 30140-100 - Belo Horizonte, MG \\ ${ }^{2}$ Escola de Veterinária da UFMG - Belo Horizonte, MG \\ ${ }^{3}$ Bunge Fertilizantes - Chapecó, PR
}

\begin{abstract}
RESUMO
Analisou-se a atividade enzimática in vitro de uma lipase em diferentes condições de temperatura (simulando o processo de peletização) e pH (acidez gástrica) e na presença de íons minerais e metálicos. Para avaliar a estabilidade térmica, a enzima foi incubada a $80^{\circ} \mathrm{C}$ por quatro tempos $(0,5,10$ e 15 minutos). $\mathrm{O}$ efeito do $\mathrm{pH}$ foi estudado submetendo-se a enzima a quatro valores de $\mathrm{pH}(7,3,2,0,3,2 \mathrm{e}$ 5,0). Para avaliar o efeito da lipase na presença de íons minerais e metálicos, incubou-se a enzima em diferentes soluções contendo cálcio, cobre, cobalto, manganês e ferro. Frente às diferentes condições, a lipase conservou atividade parcial, mas não pôde ser considerada uma enzima ideal em função do efeito inibidor promovido pelo $\mathrm{pH}$ ácido e pelas soluções iônicas testadas.
\end{abstract}

Palavras-chave: atividade, lipase, íons, $\mathrm{pH}$, temperatura

\begin{abstract}
The in vitro catalytic activity of a lipase was assessed in different conditions of temperature (simulating that of pelleted ration manufacturing), $\mathrm{pH}$ (gastric acidity), and its stability in the presence of metallic and mineral ions. To assess the thermal stability, the enzyme was incubated for 0, 5, 10 or 15 minutes at $80^{\circ} \mathrm{C}$. The effect of $\mathrm{pH}$ was studied by submitting the lipase to $\mathrm{pH}$ values of 7.3, 2.0, 3.2 or 5.0. In order to evaluate the catalytic activity in the presence of metallic and mineral ions, the enzyme was incubated in solutions containing calcium, copper, cobalt, manganese and iron. In the above mentioned conditions, the lipase partially preserved its activity, but, could not be considered an ideal enzyme due to its inhibition by the acidic $p H$ and the ionic solutions tested.
\end{abstract}

Keywords: activity, lipase, ions, $\mathrm{pH}$, temperature

\section{INTRODUÇÃO}

O principal objetivo do uso de enzimas exógenas na alimentação animal é permitir a otimização dos nutrientes de diferentes ingredientes alimentares que apresentem baixo coeficiente de digestibilidade, resultantes da própria composição ou das próprias características do animal (Nunes, 1995). A maior flexibilização de dietas, com diminuição dos custos e manutenção das características produtivas (Brenes et al., 1996), pode ser obtida com emprego de enzimas exógenas.

A suplementação dessas enzimas na alimentação de não-ruminantes pode suprir deficiências enzimáticas dos animais e melhorar a utilização de matérias-primas, bem como permitir o uso de produtos alternativos (Piquer, 1996).

Recebido para publicação em 29 de julho de 2004

Recebido para publicação, após modificações, em 29 de dezembro de 2004

E-mail: vanusa.ferreira@fead.br 
A literatura abordando o uso de enzimas na alimentação de coelhos é escassa. Assim, os efeitos das enzimas sobre o material fibroso consumido e sua capacidade de digeri-lo e aproveitá-lo são de suma importância (Cheeke et al., 1986).

A necessidade de consumo elevado de alimentos para suprir a alta necessidade metabólica dos animais de pequeno porte faz com que a passagem de alimentos pouco digestíveis e com elevado nível de fibra e lignina, através do sistema digestivo, seja rápida. No caso dos herbívoros, devido ao tipo de alimentação que recebem (alimentos com elevado nível de fibra e lignina), a velocidade de trânsito determina a baixa digestibilidade da fibra, pois o potencial celulolítico da microflora do aparelho digestivo está estreitamente relacionado com o tempo de retenção do alimento (Fraga e Carabaño, 1989).

As lipases usadas como suplemento dietético podem potencializar o uso de óleos ou gorduras, o que resultará em interessante e inovador procedimento combinado para a formulação de dietas completas para coelhos.

As enzimas são produzidas por meio de culturas aeróbicas, derivadas de fermentações fúngica, bacteriana e de leveduras (Broz et al., 1994) em condições de processamento muito bem controladas. A produção dessas enzimas envolve processos como fermentação, extração, separação e purificação. A extração consiste na separação da enzima de sua biomassa geradora. Segundo Inborr et al. (1991) e Vanbelle (1992), somente pequeno número de bactérias e fungos é empregado para produzir praticamente todas as enzimas industriais comuns. As enzimas utilizadas são, em sua maioria, de origem fúngica e estáveis à temperatura ambiente, porém inativam-se rapidamente em temperaturas superiores a $60^{\circ} \mathrm{C}$. A estabilidade da enzima é superior quando incorporada no alimento (Francesch, 1996, citado por Borges, 1997), mas o calor da peletização pode inativar as enzimas. Assim, uma enzima ideal deve ser capaz de suportar temperaturas entre 70 e $90^{\circ} \mathrm{C}$, normalmente alcançadas durante o processo de peletização (Finnfeeds, 1991).

De acordo com o método de extração Novo Nordisk, o nível de atividade enzimática é mantido durante três meses em produtos líquidos e por seis meses na forma de pó, quando estocados em temperaturas inferiores a $25^{\circ} \mathrm{C}$. Quando a enzima encontra-se misturada na dieta, sua atividade pode ser mantida por, no mínimo, três meses a $25^{\circ} \mathrm{C}$ (Cowan, 1993).

O objetivo deste trabalho foi testar uma lipase comercial em diferentes condições de temperatura (processo de peletização), diferentes $\mathrm{pH}$ (simulando acidez gástrica) e estabilidade na presença de íons metálicos, bem como verificar sua atividade catalítica.

\section{MATERIAL E MÉTODOS}

A reatividade da lipase foi quantificada quando exposta à temperatura semelhante à ocorrida no processo de peletização das dietas, a variadas soluções de $\mathrm{pH}$ de ácido a alcalino, simulando as variações de $\mathrm{pH}$ do trato gastrintestinal, e a soluções contendo íons metálicos comuns às dietas de coelhos. Os testes de reatividade da lipase foram realizados em amostras originais das mesclas comercializadas pelos diferentes fabricantes, de maneira que se pôde assegurar a melhor caracterização possível, bem como clareza e evidência da atividade do produto para uso nesta pesquisa.

A quantificação da atividade da enzima foi feita de acordo com a fórmula (Manual, 2001) expressa em unidade de atividade (UA), determinada como micromoles $(\mu \mathrm{mol})$ de ácido graxo liberado por minuto, utilizando-se o método titulométrico com $\mathrm{NaOH}$ adaptado. A reação enzimática foi processada em erlenmeyers de $125 \mathrm{ml}$, em banho-maria com temperatura controlada a $37^{\circ} \mathrm{C}$.

Para cada tratamento foram realizadas triplicatas das provas reais e um teste em branco.

Colocaram-se $0,15 \mathrm{~g}$ da enzima em tubos de vidro que, em seguida, foram incubados em banhomaria a $80^{\circ} \mathrm{C}$ por quatro tempos $(0,5,10$ e 15 minutos), com três repetições cada. $\mathrm{O}$ tratamento sem calor ( 0 minuto) foi utilizado como controle e sua atividade relativa, medida como $100 \%$. Logo após o choque térmico, determinou-se a atividade lipásica, segundo a técnica descrita anteriormente.

A fim de obter os valores de $\mathrm{pH}$ de 2,0, 3,2, 5,0, e 7,3 para a determinação da estabilidade da enzima em condições simuladas de acidez do 
trato gastrintestinal, utilizou-se o tampão TRIS de $\mathrm{pH} 7,3$, ao qual foi adicionado HCL $6 \mathrm{~N}$ e/ou $\mathrm{NaOH} 4 \mathrm{~N}$, até a obtenção do pH desejado. As misturas obtidas foram incubadas a $40^{\circ} \mathrm{C}$ por 30 minutos, fazendo-se três repetições por tratamento. Após a incubação, os valores de $\mathrm{pH}$ foram ajustados para 8,0 , e as atividades, determinadas segundo a técnica descrita anteriormente.

Adicionou-se $0,1 \mathrm{ml}$ de soluções concentradas de vários íons metálicos $\left(\mathrm{MnSO}_{4}, \mathrm{FeSO}_{4}, \mathrm{CoSO}_{4}\right.$, $\mathrm{CuSO}_{4}, \mathrm{MgSO}_{4}, \mathrm{CaCl}_{2}$ e solução com todos os íons) a $0,15 \mathrm{~g}$ da lipase, apresentando, cada uma, concentração final de $5 \mathrm{mM}$. A solução do complexo enzimático (CE) sem adição de minerais foi utilizada como controle, sendo a sua atividade relativa considerada como $100 \%$. Essas misturas foram incubadas a $25^{\circ} \mathrm{C}$ por 30 minutos, sendo pipetados $0,2 \mathrm{ml}$ da solução para realizar o teste de atividade lipásica.
Nos ensaios de determinação da atividade lipásica, o delineamento experimental foi inteiramente ao acaso, e os dados submetidos à análise de variância pelo SAS (User's..., 1996), sendo as médias comparadas pelo teste de Student-Newman-Keuls a 5\% de significância. O modelo estatístico geral para o estudo dessa estabilidade foi:

$\gamma=\mu+T_{i}+E_{i}$, em que:

$\gamma=$ observação relativa ao tratamento $\mathrm{i}$;

$\mu=$ média geral;

$\mathrm{T}_{\mathrm{i}}=$ efeito do tratamento $\mathrm{i}, \mathrm{i}=$ temperatura, $\mathrm{pH} \mathrm{e}$ presença de íons metálicos; e

$E_{\mathrm{i}}=$ erro aleatório associado a cada observação.

\section{RESULTADOS E DISCUSSÃO}

Os resultados referentes à atividade da lipase, incubada a $80^{\circ} \mathrm{C}$, em diferentes tempos, são apresentados na Tab. 1.

Tabela 1. Atividade (UA/mg de proteína bruta da enzima) da lipase incubada a $80^{\circ} \mathrm{C}$ em diferentes tempos

\begin{tabular}{lcccc}
\hline & \multicolumn{4}{c}{ Tempo de incubação a 800C (minutos) } \\
\cline { 2 - 5 } & 0 (Controle) & 5 & 10 & 15 \\
\hline Atividade & $10.333,33 \mathrm{a}$ & $8.666,66 \mathrm{ab}$ & $7.333,33 \mathrm{~b}$ & $8.666,66 \mathrm{ab}$ \\
Atividade relativa (\%) & 100,00 & 83,87 & 70,97 & 83,87 \\
CV $=11,9 \%$ & & & &
\end{tabular}

Médias seguidas por letras distintas na linha diferem entre si pelo teste $\mathrm{SNK}(\mathrm{P}<0,05)$.

Nos diferentes tempos em que a enzima foi incubada a $80^{\circ} \mathrm{C}$, sua atividade catalítica variou $(\mathrm{P}<0,05)$, ou seja, a enzima pode-se desnaturar, diminuindo o seu poder catalítico. A atividade relativa da enzima não foi menor que $70 \%$, podendo ser considerada ainda como enzima ideal (Finnfeeds, 1991). Resultados semelhantes foram anteriormente encontrados por $\mathrm{Yu}$ e Tsen (1993) que, ao testarem a estabilidade térmica de papaína, bromelaína, proteases e celulases, nas mesmas condições deste experimento, encontraram atividades relativas maiores que $60 \%$ em todas as enzimas utilizadas. Estes resultados sugerem que no processo de produção a enzima pode ter sido protegida contra o efeito desnaturante do processo de peletização, já que a desnaturação foi somente parcial.

Os resultados referentes à atividade da lipase incubada a $37^{\circ} \mathrm{C}$, em diferentes valores de $\mathrm{pH}$, encontram-se na Tab. 2.

Tabela 2. Atividade (UA/mg de proteína bruta da enzima) de uma lipase incubada a $37^{\circ} \mathrm{C}$, em diferentes valores de $\mathrm{pH}$

\begin{tabular}{|c|c|c|c|c|}
\hline & \multicolumn{4}{|c|}{$\mathrm{pH}$} \\
\hline & 7,3 ( Controle) & 5,0 & 3,2 & 2,0 \\
\hline Atividade & $10.333,33 a$ & $3.000 \mathrm{~b}$ & $2.666,66 \mathrm{~b}$ & $1.333,33 \mathrm{c}$ \\
\hline Atividade relativa $(\%)$ & 100,00 & 29,03 & 25,80 & 12,90 \\
\hline
\end{tabular}

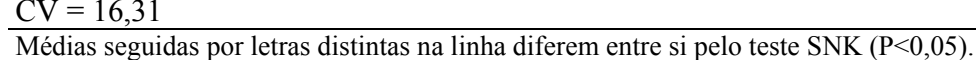


Observou-se diferença significativa $(\mathrm{P}<0,05)$ entre os diferentes valores de $\mathrm{pH}$, evidenciando que, quanto mais ácido o $\mathrm{pH}$, menor a atividade catalítica da enzima. As atividades relativas dos $\mathrm{pH}$ 2,0, 3,2 e 5,0 foram muito baixas (menos de $30 \%$ ), indicando que a enzima talvez não possa manter atividade até a passagem pelo estômago dos coelhos, não contribuindo com o processo digestivo.

Os resultados referentes à atividade da lipase incubada a $37^{\circ} \mathrm{C}$ em diferentes soluções minerais encontram-se na Tab. 3 .

Tabela 3. Atividade (UA/mg de proteína bruta) da lipase incubada a $37^{\circ} \mathrm{C}$, em diferentes soluções minerais

\begin{tabular}{|c|c|c|c|c|c|c|c|}
\hline & \multicolumn{7}{|c|}{ Solução mineral (5 mM) } \\
\hline & Controle & MnSO4 & FeSO4 & CoSO4 & $\mathrm{CuSO} 4$ & $\mathrm{CaCl} 2$ & Todos íons \\
\hline Atividade & $10.333,33 \mathrm{a}$ & $4.333,33 \mathrm{~b}$ & $2.333,33 \mathrm{~b}$ & $2.666,66 \mathrm{~b}$ & $2.666,66 \mathrm{~b}$ & $4.333,33 \mathrm{~b}$ & $4.000 \mathrm{~b}$ \\
\hline $\begin{array}{l}\text { Atividade } \\
\text { relativa }(\%) \\
\mathrm{CV}=17,25\end{array}$ & 100,00 & 41,93 & 22,58 & 25,81 & 25,81 & 41,93 & 38,71 \\
\hline
\end{tabular}

A presença de íons metálicos surtiu efeito inibitório $(\mathrm{P}<0,05)$ sobre a atividade da lipase. A atividade relativa da enzima exposta a todas as soluções iônicas foi menor que $42 \%$, sendo ferro o íon que mais prejudicou a atividade catalítica da enzima, o que pode ser atribuído à complexação desses íons com a lipase, impedindo sua atividade catalítica normal. Resultados inibitórios semelhantes aos do zinco, ferro e cobre foram encontrados por $\mathrm{Yu}$ e Ysen (1993) sobre a atividade da papaína e parcialmente inibitório sobre a atividade da bromelaína.

\section{CONCLUSÕES}

A lipase estudada pode permanecer ativa após a exposição a $80^{\circ} \mathrm{C}$, comum durante o processo de peletização, mas, em meios com $\mathrm{pH}$ ácido, como no estômago, e na presença de íons metálicos como ferro, manganês, cobalto, cobre e cálcio, a enzima não pode exercer sua capacidade catalítica com eficiência.

\section{REFERÊNCIAS BIBLIOGRÁFICAS}

BORGES, F.M.O. Utilização de enzimas em dietas avícolas. Cad. Tec. Esc. Vet. UFMG, v.20, p.5-30, 1997.

BRENES, A.; LÁZARO, R.; GARCIA, M. et al. Utilización pratica de complejos enzimaticos en avicultura. In: CURSO DE ESPECIALIZACIÓN AVANCES EN NUTRICIÓN Y ALIMENTACION ANIMAL, 22., 1996, Madrid. Anais... Madrid: FEDNA, 1996. p.134157.

BROZ, J.; OLDALE, P.; PERRIN-VOLTZ, A.H. Effects of supplemental phytase on performance and phosphorus utilization in broiler chickens fed a low phosphorus diet without addition of inorganic phosphates. Br. Poult. Sci., v.35, p.273-280, 1994.

CHEEKE, P.R.; GROBNER, M.A.; PATTON, N.M. Fiber digestion and utilization in rabbits. $J$. Appl. Rabbit Res., v.9, p.25-30, 1986.

COWAN, W.D. Understanding the manufacturing, distribuition, application and overall quality of enzymes in poultry feeds. $J$. Appl. Poult. Res., v.2, p.93-95, 1993.

FINNFEEDS Internacional. Enzymes in animal nutrition. England: Technical Support Manual, 1991. p.11-16.

FRAGA, M.J.; CARABAÑO, R. Coprofagia. In: DE BLAS, J.C. (Ed.) 2.ed. Alimentación del conejo. Madri: Mindi-Prensa, 1989. p.15-27.

FRANCESCH, M. Bases de la utilización de complejos enzimáticos en avicultura. In: CURSO DE ESPECIALIZACIÓN AVANCES EN NUTRICIÓN Y ALIMENTACIÓN ANIMAL, Madrid. Anais... Madrid: FEDNA, 1996. p.118131. 
INBORR，J.; GRAHAM，H.; NISSINEN， V. Selección, producción, estabilización y control de calidad de las enzimas alimentárias. In: SEMINÁRIO SOBRE EL EMPLEO DE ENZIMAS EN LA NUTRICIÓN ANIMAL, 1991, Madrid. Anais...Madrid: [s.n.], 1991. Pb.15.

MANUAL Sigma-Aldrich. Biochemicals and reagents for life science research. : [s.f. : s.n.], 2000/2001. 2843p.

NUNES, C.N. Enzimas em nutrição animal: conceitos, factos e perspectivas. Rev. Port. Ciên. Vet., v.90, p.10-18, 1995.

PIQUER, P.J. Bases del utilización de complejos enzimáticos en nutrición animal: estudio comparativo entre especies. In: CURSO DE ESPECIALIZACIÓN FEDNA - AVANCES EN NUTRICIÓN Y ALIMENTACIÓN ANIMAL, 12., 1996, Madri.

USER'S guide: statistics. Cary, NC: SAS Institute, 1996.

VANBELLE, M. Les enzimes probiotiques. Curso Superior de Nutrición y Alimentación Animal, Instituto Agronómico Mediterráneo de Zaragoza, 1992. (Documento Interno).

YU, B.; TSEN, H.Y. In vitro assessment of several enzymes for the supplementation of rabbit diets. Anim. Feed Sci. Technol., v.40, p.309-320, 1993. 